$\xi=-1$

\title{
The Application of GIS-AHP Technique in Analysing the Level of the Environmental Condition of Forested Areas
}

\author{
M.Zainora Asmawi ${ }^{1}$, Najihah Ngaimin ${ }^{1}$, Noor Zalina Mahamod², Norzailawati Mohd Noor ${ }^{1}$, \& Hamdan Omar ${ }^{3}$ \\ ${ }^{1}$ International Islamic University Malaysia, Jalan Gombak 53100 Kuala Lumpur, Malaysia \\ 2University Malaya, Lembah Pantai, 50603, Kuala Lumpur, Malaysia \\ ${ }^{3}$ Forest Research Institute Malaysia, Kepong, 52109, Selangor, Malaysia \\ *Corresponding author E-mail: zainora@iium.edu.my
}

\begin{abstract}
Forests are major resources that offer a strong artistic, cultural, biological and economical source for the social community in every nation. Degradation of the environmental condition has become a key concern, and the primary cause of this trouble is linked primarily to human disturbance towards natural resources. Therefore, this research was embarked to analyse the level of the environmental status of forested areas in Forest Research Institute Malaysia (FRIM), Selangor, Malaysia-based on chosen measures. This research depends on a series of GIS database covering five criteria, namely slope, altitude, crown perimeter, tree height and carbon stock, which were then analysed using Analytic Hierarchy Process (AHP). A scoring system was developed from eigenvalue of priority ratings and bringing out a composite map, showing the level of the environmental condition of the forest, ranging from the healthiest, moderately healthy and less healthy condition. The results indicate that $45.5 \%$ of the forested areas in FRIM lie under the category of healthiest condition (220.8 hectares) with the carbon stock as the key contributor. This research concludes that the relevant criteria for ecosystem health are beneficial in monitoring the forest condition that contributes to the environmental quality with particular reference to the consideration of forest as an impactful carbon sink element of any geographical setting.
\end{abstract}

Keywords: Environmental Condition, GIS-AHP Technique, Composite Map

\section{Introduction}

Forestry is essential to many environmental, ecological, aesthetic, cultural, biological and economical services [1]. Besides providing habitat for wildlife, forest ecosystems are also the sources of wood, timber and various edible products for human endurance. Other than that, forests are also one of the important factors in the global cycling of carbon, oxygen, and other gasses which influence the composition of the earth's air. Nevertheless, a forest can deliver the functions of security or conservation expected from it exclusively if it is either under good natural ecological conditions or when in use, it is made out in a sustainable way.

Degradation of environmental health condition has become a serious issue that developing nations are facing today, and this is induced by some influential factors. The primary cause of this environmental degradation is human disturbance towards natural resources, especially in forested areas. Thus, this situation should not be taken for granted as forestry areas are one of the ultimate natural resources that give the contribution to a healthy environment as a whole.

Therefore, this research was embarked to analyse the level of the environmental status of forested areas in Forest Research Institute Malaysia (FRIM), Selangor, Malaysia.

\section{Problem Statement}

Presently, Selangor is the most developed state in Malaysia, contributing more than $23 \%$ of GDP nationally (2010). However, it faces the challenge to balance between conservation efforts on the environmental resources of forest and its socioeconomic growth. Even though Selangor is an urbanised state, the number of forest reserve areas is numerous with the total area of 148,324 hectares, covering more than $30 \%$ of the state (Ministry of Natural Resources and Environment Malaysia, 2013). Over the years, there are many environmental issues occurred in Selangor such as flash floods, loss of mangrove and so forth. Bukit Lagong Permanent Forest Reserve (PFR) which was in FRIM area is one of the forest reserves in Selangor that is currently facing these environmental issues. At the international level, there are different methods used in GIS and remote sensing to identify the health condition of whatever natural resources as studied by [2][3][4][5]. Whereas, in the local context, currently there is a lack of research on the level of the environmental condition of natural resources, for instance, forested areas [6].

\section{The aim of Research}

The aim of this research is to analyse the level of the environmental condition of forested areas in FRIM campus. This purpose contributes to the objectives which are: to identify the criteria that lead to its environmental method; and to examine the status of the level of forested areas in FRIM campus. 


\section{Method of Research}

This research applied descriptive analysis to analyse the level of the environmental condition based on the selected criteria [7]. The analysis stage depends highly on the GIS and AHP process. AHP is a technique that offers a comprehensive and rational framework for structuring a decision problem [8]. This method provides a social system for the establishment and evaluation of the importance of different standards and preference of choices for the decision makers, to facilitate the decision-making process. AHP is used depending four orderly principles:

1. Decompose the problem into a hierarchy of goal, criterion, and alternatives

2. Evaluate the elements of the hierarchy by a pairwise comparison method

3. Obtain a numerical priority for each element of the hierarchy, allowing diverse and often incompatible elements to be compared in a rational and consistent way

4. Calculate the numerical priorities for each of the decision alternatives

The development of an AHP model that has been made employing the three principles of AHP technique. The model consists of the level of environmental condition, choices of criteria and classifications of each criterion. The selected criteria used are the slope, altitude, crown diameter, tree height and carbon stock. The datasets of 54 fields in FRIM Campus were obtained from FRIM for the running of the GIS-AHP analysis. The rule of comparative judgment requires assessment of pairwise comparisons of the criteria with its respective classifications. Five criteria were identified for selection of the health condition of the forested area to be used to support the model. All of the criteria are separated into three classifications to be assessed as indicated in Table 1 .

Table 1: The criteria and its classification

\begin{tabular}{|c|c|c|}
\hline & Criteria & Classification* \\
\hline \multirow[t]{3}{*}{1} & \multirow[t]{3}{*}{ Slope } & Flat $\left(<10^{\circ}\right)$ \\
\hline & & Moderate $\left(10^{\circ}-25^{\circ}\right)$ \\
\hline & & Steep $\left(>25^{\circ}\right)$ \\
\hline \multirow[t]{3}{*}{2} & \multirow[t]{3}{*}{ Altitude } & Mountainous $(>300 \mathrm{~m})$ \\
\hline & & Hilly $(100 m-300 m)$ \\
\hline & & Lowland $(<100 \mathrm{~m})$ \\
\hline \multirow[t]{3}{*}{3} & \multirow[t]{3}{*}{ Crown diameter } & Large $(>10 \mathrm{~m})$ \\
\hline & & Medium ( 5-10m) \\
\hline & & Small $(<5 \mathrm{~m})$ \\
\hline \multirow[t]{3}{*}{4} & \multirow[t]{3}{*}{ Tree height } & Tall $(>15 \mathrm{~m})$ \\
\hline & & Medium (10-15m ) \\
\hline & & Short $(<10 \mathrm{~m})$ \\
\hline \multirow[t]{3}{*}{5} & \multirow[t]{3}{*}{ Carbon stock } & High ( 70\% ) \\
\hline & & Medium ( $30 \%-70 \%)$ \\
\hline & & Low $(<30 \%)$ \\
\hline
\end{tabular}

Note: * the classification was arranged depending on its importance of contributing to the level of environmental condition. It means that the sequence of different of classification indicating the degree of environmental condition, ranging from the healthiest, moderately healthy to less healthy.

Later on, the AHP techniques have been exercised, and the criteria were classified in the strain of over layering maps using the GIS technique. As a result, all plans are overlaid to produce a composite map. The level of the health condition of forestry area can be retrieved through a composite score from eigenvalue of priority ratings.

FRIM is located in Kepong, Selangor and covers 485.2 hectares (Figure 1). Most of the forest trees standing is planted the forest, and the area is skirted by the Bukit Lagong Forest Reserve. 420.11 hectare land at FRIM are covered by forest which $90.4 \%$ of the area is planted the forest and the remaining of $9.6 \%$ hectare is a natural forest. Most of the trees were established following the year of 1929, and the age is estimated close to 80 years previous.

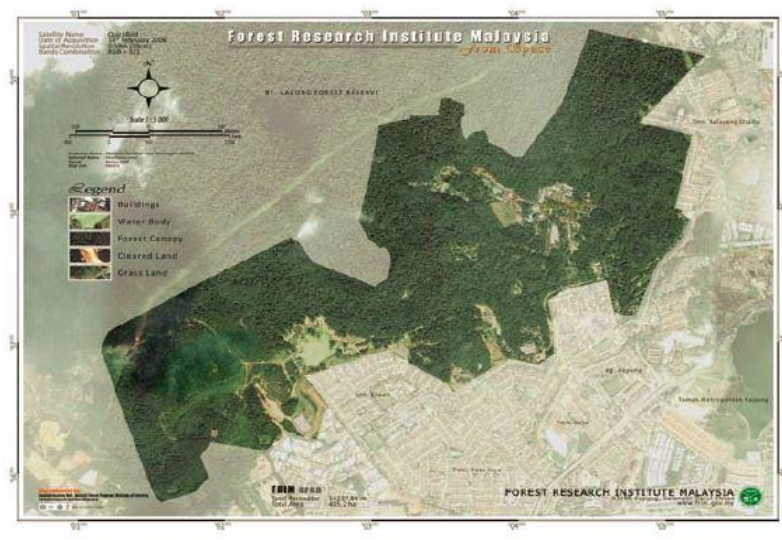

Figure 1: Field boundaries of FRIM campus Source: Forest Research Institute Malaysia (2015)

\section{Results and Discussion}

The application of the GIS-AHP model is to analyse the environmental condition of the forested area at the FRIM campus to facilitate the environmental planning of Selangor for further development control at the state and local planning authorities. Table 2 and Figure 2 show the results of the priority weight using the AHP process and the GIS technique calculated the eigenvalue for each criterion. In the GIS operation, the criteria and its classifications measurement were separately mapped and sorted accordingly. The global eigenvalues were then specified in the GIS attributes. All plans were covered to produce the last effect of the composite map (Figure 3). Areas indicated as the healthy forest that receives a sound point of environmental forestry condition can be retrieved through a serial publication of the composite score.

Table 2: Priority weightage results

\begin{tabular}{|l|l|l|}
\hline Criteria \& Classification & $\begin{array}{l}\text { Eigenvalue } \\
\text { (local) }\end{array}$ & $\begin{array}{l}\text { Eigenvalue } \\
\text { (global) }\end{array}$ \\
\hline Slope & $\mathbf{0 . 0 4 7}$ & $\mathbf{0 . 0 4 7}$ \\
\hline Flat $\left(<10^{\circ}\right)$ & 0.105 & 0.005 \\
\hline Moderate $\left(10^{\circ}-25^{\circ}\right)$ & 0.258 & 0.012 \\
\hline Steep $\left(>25^{\circ}\right)$ & 0.637 & 0.030 \\
\hline Altitude & $\mathbf{0 . 0 2 7}$ & $\mathbf{0 . 0 2 7}$ \\
\hline Mountainous $(>300 \mathrm{~m})$ & 0.637 & 0.017 \\
\hline Hilly $(100 \mathrm{~m}-300 \mathrm{~m})$ & 0.0258 & 0.007 \\
\hline Lowland $(<100 \mathrm{~m})$ & 0.105 & 0.003 \\
\hline Crown perimeter & $\mathbf{0 . 1 4 5}$ & $\mathbf{0 . 1 4 5}$ \\
\hline Large $(>10 \mathrm{~m})$ & 0.649 & 0.094 \\
\hline Medium $(5-10 \mathrm{~m})$ & 0.279 & 0.040 \\
\hline Small $(<5 \mathrm{~m})$ & 0.072 & 0.010 \\
\hline Tree height & $\mathbf{0 . 0 8 1}$ & $\mathbf{0 . 0 8 1}$ \\
\hline Tall $(>15 \mathrm{~m})$ & 0.637 & 0.051 \\
\hline Medium $(10-15 \mathrm{~m})$ & 0.258 & 0.021 \\
\hline Short $(<10 \mathrm{~m})$ & 0.105 & 0.008 \\
\hline Carbon & $\mathbf{0 . 3 9 7}$ & $\mathbf{0 . 3 9 7}$ \\
\hline High $(70 \%)$ & 0.669 & 0.265 \\
\hline Medium $(30 \%-70 \%)$ & 0.243 & 0.096 \\
\hline Low $(<30 \%)$ & 0.088 & 0.035 \\
\hline & & \\
\hline
\end{tabular}




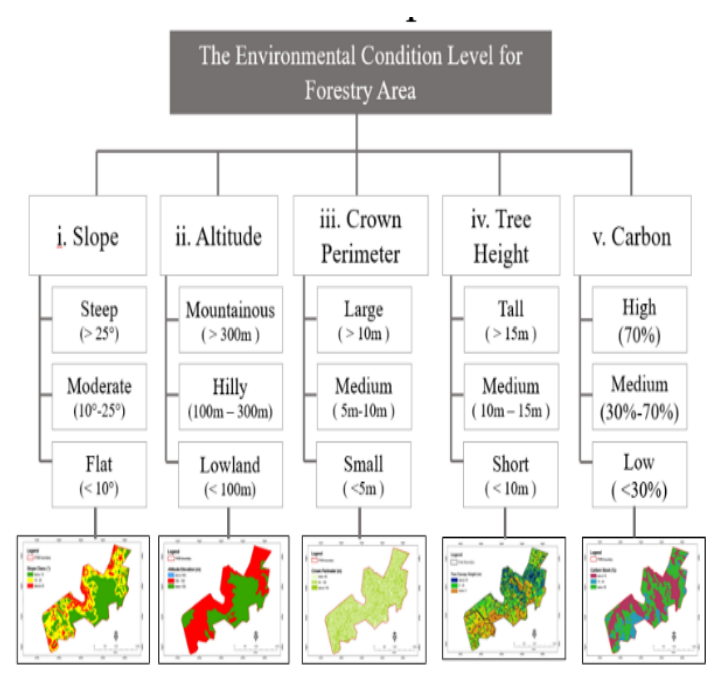

Figure 2: Gathering database for all the criteria in the form of plans

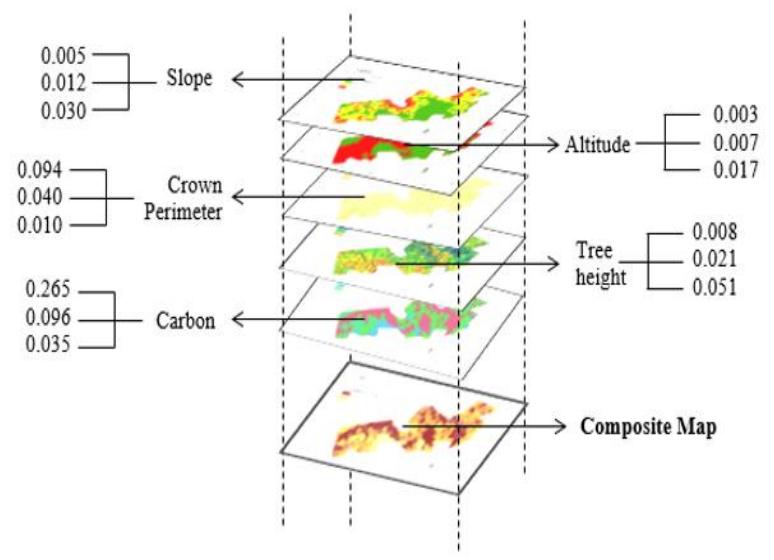

Figure 3: GIS mapping over layering process

The overall results combining the five criteria to identify the level of the environmental status of the forested area are depicted in Figure 4. This image illustrates the final composite map result showing areas that are assorted as the healthiest, moderately healthy and less healthy condition (Table 3 ).

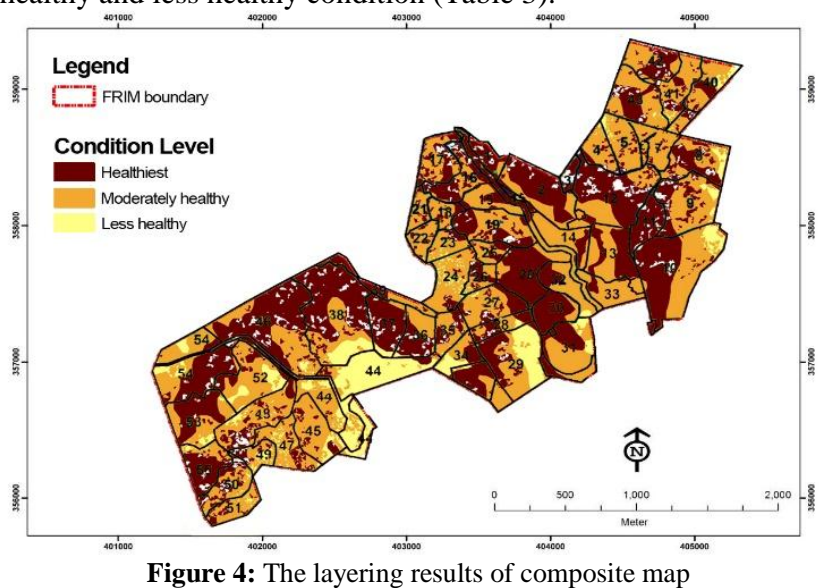

Table 3: GIS multicriteria analysis result

\begin{tabular}{|l|c|c|}
\hline Description for Forestry Healthy Level & $\begin{array}{c}\text { Area } \\
\text { (ha.) }\end{array}$ & \% \\
\hline $\begin{array}{l}\text { The healthiest (Within the range of natural } \\
\text { variability, exhibiting the normal composi- } \\
\text { tion, structure and function) }\end{array}$ & 220.8 & 45.5 \\
\hline
\end{tabular}

\begin{tabular}{|l|l|l|}
\hline $\begin{array}{l}\text { Moderately healthy (Departing from natural } \\
\text { ranges of variability, trends suggest an irreg- } \\
\text { ular composition, structure and function) }\end{array}$ & 218.8 & 45.1 \\
\hline $\begin{array}{l}\text { Less healthy (Significant departure from the } \\
\text { natural range of variability or normal levels, } \\
\text { suggest highly abnormal characteristics in } \\
\text { composition, structure and function) }\end{array}$ & 45.6 & 9.4 \\
\hline Total & 485.2 & 100 \\
\hline
\end{tabular}

The analysis result of the composite map gives the indication that the forested areas in FRIM campus are vigorously healthy and suitable for natural resource preservation because the highest percentage coverage, which is $45.5 \%$ of the site is under the category of healthiest condition with the area of 220.8 hectares. Furthermore, it can be determined from the mapping result that the total of 16 fields division under this healthiest category. This situation indicates that the environmental condition of FRIM area is seen every bit within an arena of natural variability, showing the natural makeup, structure, and function of forested areas. While the second highest coverage category is moderately healthy, this is $45.08 \%$ of the area of 218.8 hectares consisting of 18 fields. The moderately healthy category is departing from natural ranges of variability, trends suggest an irregular composition of structure and function. The least coverage percentage is the less healthy category which is $9.39 \%$ of the area of 45.6 hectares covering four fields. This category has the significant departure from the natural range of variability or normal levels, highly unusual characteristics in composition, structure, and function.

Besides that, the result proves that this forest can accommodate current and future needs, values, products and services for the community as a whole. This finding leads to the idea about the importance of the criteria chosen as the indicator to determine the environmental forestry condition. Other indicators such as geographical factor, climate, temperature and biological features would give a better detail result of the research.

This survey also indicates that carbon stock plays an important role for a circumstance of a forest. Moreover, the other significance of interactive variables which are the slope, altitude, crown perimeter and tree height shows that the consideration of combined factors is useful for a better understanding of the forest health.

\section{Conclusion}

In general, this research seeks to use GIS-AHP method to establish a quality assessment system for a forested country to supply a valid and rational assessment of environmental condition in FRIM area. This work strives to identify the degree of the environmental condition which could be split into the healthiest, moderately healthy and less healthy. The research has successfully explored and revealed the usefulness of AHP as an efficient method to get better guidance. This, nevertheless, is not the final stage of the study since it involves many complicated factors, including weight, parameters, judgments and consistency, in which the assistance of computer software is involved in deriving the consequences for future advance. The five criteria given in this research could be extended to other relevant data such as crown shape, tree distribution, forest productivity, shrub cover, herbaceous plant cover and a lot more.

In this regards, this research indicates that it is necessary to build a scientific system for forest management, conservation and sustainable development for a nation, considering the importance of the environmental status of forested areas. This research concludes that the relevant criteria for ecosystem health are beneficial in monitoring the forest condition that contributes to the environmental quality with particular reference to the consideration of forest as an impactful carbon sink element of any geographical setting. 


\section{Acknowledgement}

This work was financially supported by the University of Malaya under Grant No. CG018-2014 with the data assistance from the Forest Research Institute Malaysia (FRIM). We also would like to thank Azraei Shahbudin for the GIS-AHP technical support.

\section{References}

[1] Stanturf, J. A., Palik, B. J., \& Dumroese, R. K. Contemporary forest restoration: A review emphasizing function. Forest Ecology and Management. 2001. 331, p. 292-323.

[2] Herrington, L. and D.E. Koten, A GIS-based decision support system for forest management, In Accessing the World, Proceedings, GIS/LIS '88, Vol. 2, San Antonio, TX, November ACSM, ASPRS, AAG, URISA. 1988. p. 825-831.

[3] Levinsohn, A.G. and S.J. Brown. GIS and sustainable development in forest management, In Applications in a Changing World, GIS '91 Symposium Proceedings, Vancouver, Canada, February 12-15, 1991. Vancouver, BC: Forestry Canada. 1991. p. 181-185.

[4] Tabor, J.A. and Hutchinson, C.F. Using indigenous knowledge, remote sensing and GIS for sustainable development. Indigenous Knowledge and Development Monitor. 1994. 2(1).

[5] Mather, R.A. Using photomaps to support participatory processes of community forestry in the Middle Hills of Nepal. Mountain Research and Development. 2000. 20 (2): p. 154-161.

[6] Forestry Department of Peninsular Malaysia, 2013. Significant Findings of Forest Biodiversity Scientific Expeditions. Retrieved 22 October, 2015, from Forestry Department of Peninsular Malaysia. 2015. http://www.forestry.gov.my.

[7] Gong, L., Zhang, Z. and Xu, C. Developing a quality assessment index system for scenic forest management: a case study from Xinshan Mountain, Suburban Beijing. Forests. 2015. 6, p. 225-243.

[8] Saaty, T.L. The Analytic Hierarchy Process: Planning Priority Setting Resource Allocation. McGraw-Hill International Book Company. United States of America. 1980. 